\title{
Cómo afecta el síndrome Lozano-Barragán y el efecto Sharknado a las organizaciones de producción cinematográficas: Analizando la trayectoria de M. Night Shyamalan (How it affects the Lozano-Barragan Syndrome and the Sharknado effect to the film productions organizations: Analyzing the path of M. Night Shyamalan)
}

\section{David Fernando Lozano Treviño* José Nicolás Barragán Codina*}

\begin{abstract}
The main purpose of this document is to state the importance of taking into consideration the desires and needs of the spectators by the film production organizations in their mission of reaching the economic success. It establishes the importance that the economic values and aesthetic values plays in the films. It locates the different degrees of the dissatisfaction in which a spectator can falls into when he or she does not like the movie. Likewise, this paper analyze the filmmaking development of M. Night Shyamalan as well as his rise, fall and new arise by suffer and then eradicate the Lozano-Barragan Syndrome and the Sharknado Effect conditions; concepts that distinguish, first: those film production organizations that blame the dissatisfied spectator, for the box office failure, as well as, they argued that those spectators did not understand the movies nor nature of it; and the second one refers the consequences that meaningless movies, more than just entertain, cause in spectators. Finally, it make some recommendations that could be followed by personal from film production organizations to avoid these Lozano-Barragan syndrome and Sharknado effect in the pursuit of the spectator satisfaction and the increase of the income in the ticket office and the aesthetic values.
\end{abstract}

Keywords: consumers, cultural industry, film production organizations, Lozano-Barragan syndrome, satisfaction, Sharknado effect

JEL: Z11, M310

\footnotetext{
- Universidad Autónoma de Nuevo León, Facultad de Contaduría Pública y Administración, San Nicolás de los Garza, N.L., México. Email: davidflozano@gmail.com

* Universidad Autónoma de Nuevo León, Facultad de Contaduría Pública y Administración, San Nicolás de los Garza, N.L., México. Email: jose.barraganc@uanl.mx
} 
Resumen: El presente documento tiene como finalidad plasmar la importancia que tiene el tomar en cuenta los deseos y necesidades de los espectadores en la misión de alcanzar el éxito económico que las organizaciones de producción cinematográfica se han impuesto. Se establece la importancia que los valores económicos y valores estéticos juegan en las películas. Se ubican los diferentes grados de insatisfacción en los que puede caer un espectador cuando no le agrada la película. Igualmente, esta investigación analiza el desarrollo cinematográfico de M. Night Shyamalan así como su crecimiento, caída y resurgimiento sufridos al padecer y, posteriormente, erradicar el Síndrome Lozano-Barragán y el Efecto Sharknado, conceptos que distinguen; primero: aquellas organizaciones de producción cinematográfica que culpan a los espectadores del fracaso en taquilla al argumentar que estos consumidores no supieron entender la película o la naturaleza del cine; el segundo hace referencia a las consecuencias provocadas en el espectador por las películas sin sentido más que sólo entretener. Finalmente, se hacen recomendaciones que pueden ser consideradas por el personal de las organizaciones de producción cinematográficas para evitar el síndrome Lozano-Barragán y el efecto Sharknado en la búsqueda de provocar satisfacción en los espectadores e incrementar los ingresos en taquillas así como los valores estéticos.

Palabras clave: consumidores, efecto Sharknado, industria cultural, organizaciones de producción cinematográfica, satisfacción, síndrome Lozano-Barragán

\section{Introducción}

Por su naturaleza, las Organizaciones de Producción Cinematográfica (OPC) son productoras de bienes culturales que buscan hacer reflexionar a los consumidores, en este caso los espectadores, pero también tienen la necesidad de incrementar sus valores económicos o las riquezas de los accionistas para cumplir la misión de cualquier compañía lucrativa y así crecer como organización asegurando la supervivencia en el mercado. Una variable para lograrlo es direccionarse a satisfacer las necesidades de los espectadores quienes, al comprar un boleto en taquilla, adquirirían la promesa incondicional de apreciar una película entretenida y con contenido que los lleve a la reflexión a algún tipo de aprendizaje.

Por lo tanto, las OPC deben llevar su mensaje cultural de una forma que resulte atractiva para los consumidores, ya sea mediante factores causales de éxito como lo son los personajes centrales, sus deseos y sicología, mediante antagonistas perversos y con deseos opuestos a los del personajes centrales o bien, haciendo un buen manejo de la tensión. Dichos factores pudieran aumentar el interés del espectador por determinado film en 
cartelera (Lozano, D. 2009). El género, los efectos visuales, los actores, directores y guionistas, entre muchos otros elementos, también son factores que suelen ser de interés al momento de tomar la decisión de compra de un boleto en taquilla.

De forma no muy acertada para la vertiente económica, algunas OPC se han enfocado sólo en producir películas donde se consideraron las preferencias del director como artista principal de la película sin efectuar un cuidadoso estudio de mercado que arroje cuáles son los deseos de entretenimiento que tienen los espectadores, como consumidores de un bien, y la manera precisa en la que las OPC hagan películas que logren satisfacer dichas necesidades del público.

Algunas de estas compañías que preferentemente plasman historias, y elementos de producción en general, que sólo tienen como fin satisfacer los egos de directores o productores de las mismas, cuando se encuentran ante un fracaso económico, argumentan que los consumidores o espectadores tienen la culpa de dicho descalabro porque no supieron entender la película 0 desconocen la naturaleza cultural del séptimo arte. Al deslindarse de su responsabilidad como productores e imputarla a los espectadores, la OPC manifiesta lo que se conoce como Síndrome Lozano-Barragán (SLB).

Es recomendable que las OPC vean a las películas no sólo como obras de arte, sino también como productos participantes de un sistema de mercado que al final serán consumidos por espectadores que buscan satisfacer sus necesidades y deseos de entretenimiento, diversión, reflexión y cultura; considerando que la película sea importante para él, tenga un atractivo emocional y que sea de interés (Assael, 1999).

En el otro extremo encontramos a las OPC que sólo producen películas con el único fin de recaudar ingresos, olvidando la naturaleza artística del cine. Estas compañías no incluyen elementos estéticos propios de la cinematografía que lleve a la reflexión, el aprecio de la belleza, la armonía o la enseñanza para el público. Los productores y directores provocan así un efecto Sharknado, que se da precisamente cuando la OPC produce filmes "huecos" o carentes de elementos dignos de ser apreciados, y que por lo tanto, carecen de contenido que estimule el aprendizaje o reflexión entre la audiencia. En este tipo de filmes la OPC únicamente pretende obtener dinero.

M. Night Shyamalan es un director, productor, guionista y empresario cinematográfico que se ha caracterizado por sus éxitos y fracasos en taquilla. 
La película Sexto Sentido (1999) fue su primera película que obtuvo atractivas recaudaciones tanto en los Estados Unidos como en el resto del mundo. Consiguió seis nominaciones al premio Óscar incluyendo mejor director y mejor guión. Con una carrera prometedora, sus películas estaban garantizadas como éxito en taquilla, más en el 2013, y después de varios desaciertos taquilleros, su película El Último Maestro del Aire (2010) fue evaluada por el portal de Internet Rotten Tomatoes, una ventana virtual donde 189 de los críticos más experimentados de los Estados Unidos califican las películas en cartelera, con un $6 \%$ de aprobación.

El cineasta había afirmado hasta entonces, que sólo se preocuparía de contar historias en el cine que sean agradables para él. Frente a los desfavorables resultados que obtuvo en taquilla, pareciera que las cosas cambiaron cuando lanzó "Los Huéspedes" (2015), película que obtuvo el 61\% de aprobación de parte de los críticos, aunado a sus declaraciones que hacen referencia a la importancia que ahora le da a los gustos de los espectadores y sus deseos de apreciar historias frente a la pantalla. A raíz de lo anterior, parece que su OPC se re direcciona, ya que de ahora en adelante ésta producirá películas que satisfagan las necesidades de entretenimiento y reflexión.

\section{Planteamiento del problema}

Algunas OPC se centran únicamente en los aspectos estéticos y culturales que los directores y productores quieren mostrar esto sin considerar los deseos y necesidades de los consumidores. Los productos de estas OPC generan insatisfacción en muchos espectadores, quienes además son culpados del fracaso en taquilla de la película cayendo así en el SLB. Esto se vuelve negativo, porque si una película es vista por un número reducido de espectadores no genera los ingresos ni el Retorno sobre la Inversión (ROI) necesarios que lleven a la empresa a ser económicamente sustentable.

Por otro lado, están aquellas OPC que únicamente buscan incrementar sus valores económicos, olvidando así su naturaleza como productores de valores estéticos inherentes a las películas, lo que desencadena entonces un efecto Sharknado. Más allá de los estudios científicos que ya abordan el concepto del SLB y el efecto Sharknado, es necesario concientizar a los productores y directores de las OPC sobre la importancia de que sus películas 
sean generadoras de valores económicos, como los ingresos en taquilla y el $\mathrm{ROI}$ necesario, asimismo de valores estéticos que lleven al aprecio de la obra, la reflexión o el aprendizaje. Casos de estudio que concienticen de lo anterior son convenientes para alcanzar el fin pretendido de creación de valor integral y auto sustentabilidad de las OPC.

\section{Objetivos}

El presente trabajo d investigación plantea los siguientes objetivos:

- Ubicar el efecto en los ingresos en taquilla y en el ROI, que provocan las producciones de las OPC que han mostrado un comportamiento acorde con el SLB

- Analizar el impacto en los ingresos en taquilla de las OPC y en el ROI, que provocan las producciones de las OPC que han elegido mostrar un efecto Sharknado.

\section{Hipótesis}

Las hipótesis planteadas son las siguientes:

H1: Las OPC que cuenten con directores que manifiesten el SLB tendrán menores ingresos en taquilla y menor ROI.

H2: Las OPC que cuenten con directores que reflejen un efecto Sharknado tendrán menores ingresos y menor ROI.

Los productores y directores de cine como ejecutivos de primer nivel en las OPC lucrativas

Las OPC crean productos que son más o menos simbólicos, fruto de la creatividad de los realizadores y del patrimonio cultural de una sociedad al englobar su identidad. En este tipo de productos es imposible disociar valor económico de valor estético y valor cultural y cada vez se vuelve más difícil mantener los históricos límites entre estos valores (Arrese, 2004). La industria cinematográfica en general, está y seguirá conformada por dos vías, la económica y la estética, que tendrán que mezclarse armónicamente para que 
estas empresas puedan avanzar satisfactoriamente hacia el éxito financiero, comercial, artístico y cultural.

Así los productos culturales, a los que las películas pertenecen, están conformados por sus valores económicos y estéticos y mediados por la naturaleza de las fuerzas de un mercado interesado en adquirirlos, obtienen sentido por la relación con lo verdadero, lo significativo, lo placentero o lo bello que los consumidores encuentran en éstos (O'Connor, 1999).

Los productos cinematográficos, juegan un papel importante en muchos países, al grado que se ha logrado consolidar una industria particular. Dichas OPC, formadoras de una propia industria tienen comportamientos propios y reglas de juego a seguir que van marcando su paso a través del tiempo y la van consolidando; tienen sus curvas de aprendizaje, generan sus economías de escala, realizan sus diferenciaciones de producto, que para este caso serían las historias que cuentan en las propias películas, crean tecnología, estrategias de mercadotecnia, entre otros. Además las OPC y toda la industria cinematográfica, son tomadas en cuenta dentro de las políticas culturales y económicas de las naciones, pues como se menciona, son productoras de valores económicos a la vez que funcionan como herramienta educativa (Lozano, 2015).

El cine forma parte de un mecanismo económico que reúne a los compradores 0 espectadores y vendedores, artistas, productores, distribuidores y exhibidores, de un bien o servicio particular, un boleto de entrada en taquilla para ver una película (McConnell, 1997). Los primeros buscarán películas que satisfagan sus necesidades, mientras que los segundos crearán productos según estas necesidades. Los países cuyas OPC han logrado la mayor satisfacción de dichas necesidades entre los espectadores, hoy por hoy han levantado industrias con elevados ingresos en taquilla (Figura 1) y alta producción de filmes (Tabla 1). Entonces, los productores y directores cinematográficos y sus OPC, al trabajar en estas dos vertientes, la estética y económica, fomentarán la cultura, inspirativa y reflexiva entre los espectadores además de incrementar la riqueza de los propietarios del negocio y generar empleos, impulsar el consumo de bienes, pago de impuestos, entre otros, que beneficiarán económicamente a la propia empresa como al país productor (Lozano, 2009). 
Figura 1. Los 10 países con mayor recaudación en concepto de boletos vendidos en el 2012. Cifras en millones de dólares.

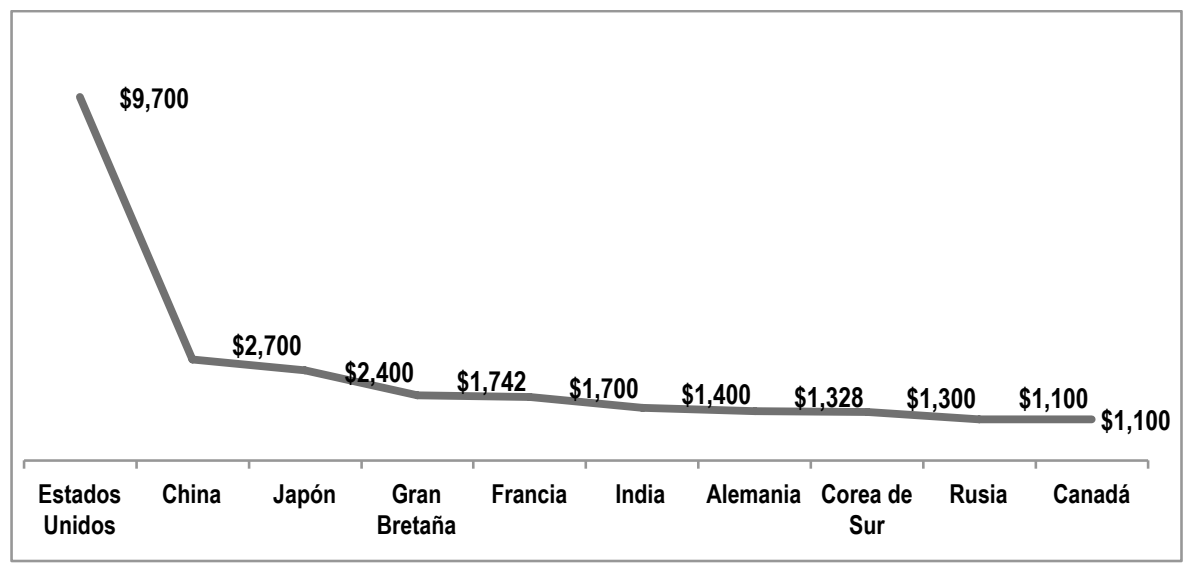

Fuente: Elaboración propia con información de la Motion Picture Association of America

Tabla 1. Los 20 mayores países productores de películas (promedio de 2005 al 2011)

\begin{tabular}{clcclc}
\hline Lugar & \multicolumn{1}{c}{ País } & $\begin{array}{c}\text { Número de } \\
\text { películas } \\
\text { producidas }\end{array}$ & Lugar & País & $\begin{array}{c}\text { Número de películas } \\
\text { producidas }\end{array}$ \\
\hline $\mathbf{1}$ & India & 1203 & 11 & Corea del sur & 137 \\
$\mathbf{2}$ & Nigeria & 967 & $\mathbf{1 2}$ & Italia & 131 \\
$\mathbf{3}$ & Estados Unidos & 757 & $\mathbf{1 3}$ & Argentina & 108 \\
$\mathbf{4}$ & China & 432 & 14 & México & 94 \\
$\mathbf{5}$ & Japón & 414 & $\mathbf{1 5}$ & Brasil & 89 \\
$\mathbf{6}$ & Rusia & 292 & 16 & Bangladesh & 88 \\
$\mathbf{7}$ & Francia & 239 & $\mathbf{1 7}$ & Filipinas & 60 \\
$\mathbf{8}$ & Gran Bretaña & 225 & $\mathbf{1 8}$ & Turquía & 49 \\
$\mathbf{9}$ & Alemania & 185 & $\mathbf{1 9}$ & Suecia & 40 \\
$\mathbf{1 0}$ & España & 175 & $\mathbf{2 0}$ & Austria & 32 \\
\hline
\end{tabular}

Fuente: Elaboración propia con información de la Motion Picture Association of America

En ocasiones, encontramos que las películas sólo buscan satisfacer la vía estética, cultural o artística de los directores quienes al contar con un ego elevado, olvidan la mitad económica comprendida en el cine que muchas veces permite llegar como producto de entretenimiento que satisface esta necesidad de ocio de las masas (Lozano et al., 2011). Parte de los espectadores sienten tedio por éste tipo de productos con enfoque en los 
valores estéticos mientras que los productores o directores, que sólo tienen la visión artística del cine, argumentan que: ... "la industria cultural sólo brinda entretenimiento bajo un hostil mandato inherente: ¡diviértete!". (Garduño, 2001) (http://.rtve.es). Incluso, los artistas en ocasiones caen en el error de culpar al espectador del fracaso comercial de este tipo de películas argumentando que éstos no saben apreciar el arte o no entendieron lo que el director 0 el productor quisieron expresar. El director debería encontrar la forma de llevar su película a las pantallas, mediante historias que resulten interesantes y contadas de una manera atractiva que no generen insatisfacción, sino que diviertan y entretengan mientras culturizan y hacen reflexionar al público (Lozano et al., 2011).

Las películas en cartelera juegan un papel donde, los espectadores al momento de adquirir un boleto en taquilla, adquieren una promesa para recibir un bien cultural con contenido que le llevará a la reflexión; más, en el otro extremo, se hace de una historia que lo entretendrá y, por qué no, le ofrecerá la diversión que busca. Las películas, al igual que cualquier producto, son bienes comprendidos bajo leyes de mercado, donde los consumidores tienen el derecho de elegir aquel que cumpla con sus expectativas.

\section{Grados de satisfacción para cubrir las necesidades de los espectadores como consumidores de un bien}

Las cadenas exhibidoras son lugares en las que se adquieren boletos en taquilla para ver películas que los espectadores hayan, o no, planeado ver (Tirmizi, 2009). Para esto, existen dos fuerzas sicológicas que atraen la atención del espectador para adquirir un boleto en taquilla (Freud, 1956):

a) El placer. Es cualquier sensación agradable producida por la realización de algo que gusta o complace (http:/buscon.rae.es). El espectador buscará que la película lo haga gozar, divertir o entretener. De alguna forma pudiéramos decir que busca un momento de felicidad, el bien propio de toda naturaleza intelectual, satisfaciendo así su necesidad cultural (de Aquino, 2010)

b) La realidad. Se refiere a la satisfacción inmediata sentida por el espectador antes y durante la proyección del film y la gratificación realmente entregada, es decir, la satisfacción que tendrá una vez que haya concluido la proyección de la película (Lozano et al., 2011). 
Algunas de las OPC que forman parte del aparato económico de los países, se encuentran administradas bajo los objetivos de incrementar las riquezas de los accionistas o dueños de la OPC mediante la satisfacción del público que aprecia la película. Un consumidor 0 espectador considera comprar un boleto para ver una película, según la motivación que tiene al momento de ver su publicidad, la cartelera de cine o los horarios de las funciones en las pantallas de las taquillas, la cercanía de una sala de cine, la capacidad económica que tiene en ese momento (recordemos que muchos espectadores no sólo compran su boleto, también llevan dinero para consumir dentro de una sala de cine), entre otros. El nombre de los actores, del director o de los productores también es un factor decisivo que influye para algunos espectadores en la compra de un boleto. Ahora, si sus motivaciones fueron altas y vio una película que cumplió con sus expectativas estará satisfecho. Si sus motivaciones fueron altas y vio una película que no cumplió con sus expectativas, estará insatisfecho (Figura 2).

Figura 2. Resultados de la satisfacción o insatisfacción del espectador motivado para ver una película en cartelera

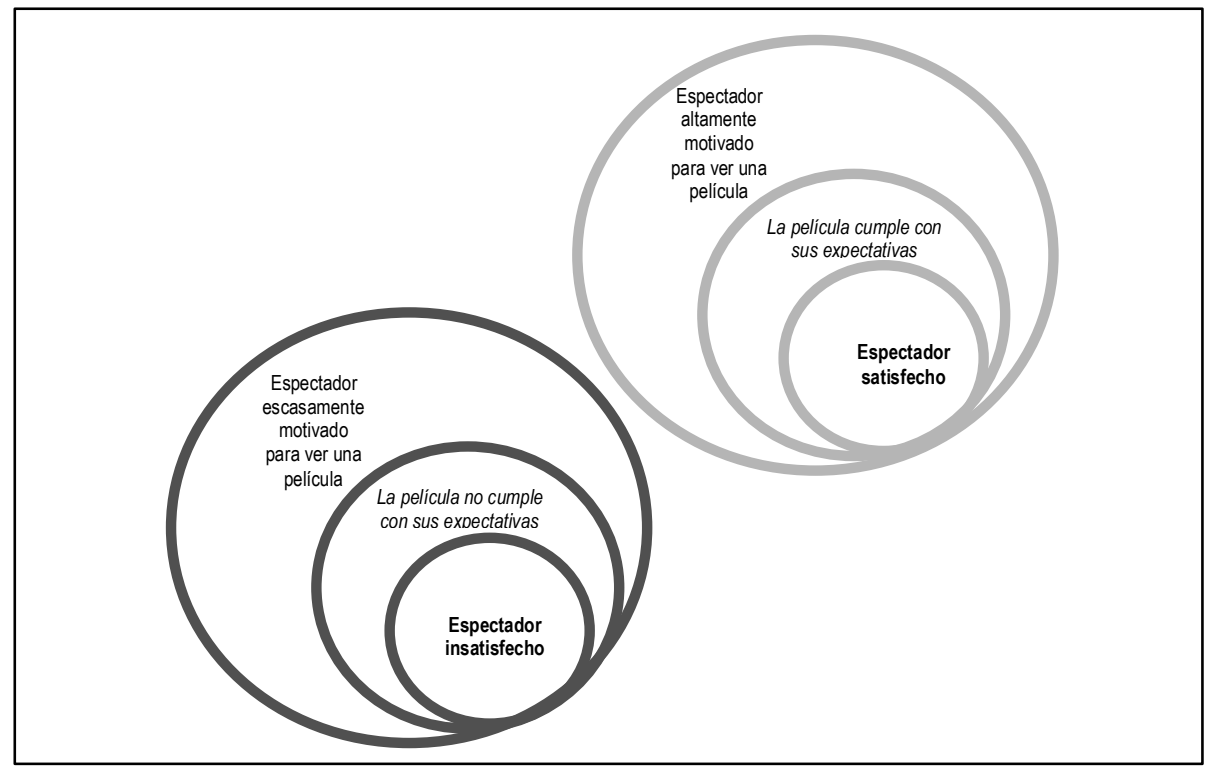

Fuente: Elaboración propia 
Evidentemente, el espectador satisfecho reacciona mediante alguna expresión de satisfacción a través de una comunicación verbal, escrita o no verbal, evaluando positivamente la película a través de algún medio de comunicación o recomendaciones de boca en boca. Una posible memorización de los creadores de la película cuyo fin será el posicionamiento positivo de los mismos como garantía de compra de boletos para futuras creaciones cinematográficas, es otra forma de reflejar dicha satisfacción.

Los grados de la satisfacción e insatisfacción de los espectadores, puede llegar a diferentes niveles según la escala propuesta en la Figura 3.

Figura 3. Escala de satisfacción que puede alcanzar un espectador

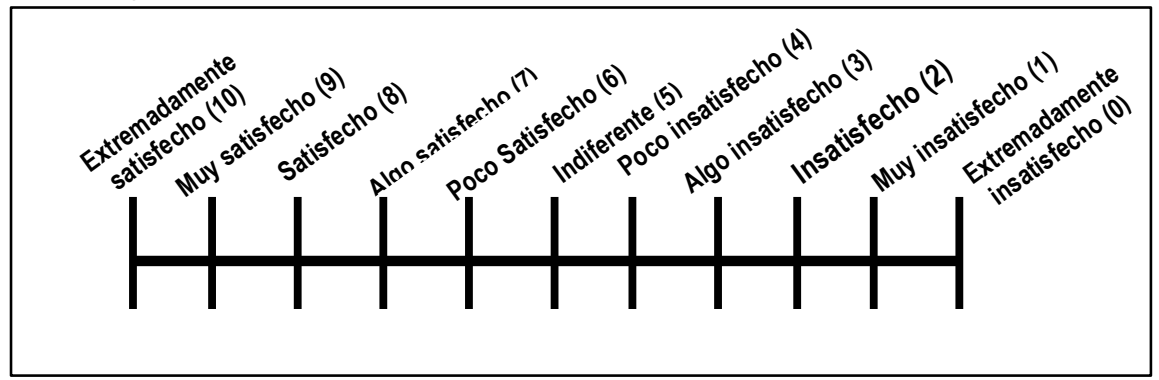

Fuente: Elaboración propia

Dichas escalas se definen:

(10) Extremadamente satisfecho. El espectador sentirá que es uno de los mejores filmes que ha visto en toda su vida. Estará al pendiente de la trayectoria de los realizadores tanto previa como posterior a la película apreciada. Es muy probable que sienta alguna admiración hacia el director del film como artista principal. Evidentemente es el grado más importante para la OPC tanto por el potencial para adquirir buenos ingresos en taquilla, maximizar el ROI y obtener una buena crítica.

(9) Muy satisfecho. El espectador pensará: "Estoy satisfecho de haber visto esta película. Me he divertido, me gustó mucho, he pasado un momento muy agradable". Probablemente busque más información sobre los productores y el director o los artistas que aparecieron en la producción para ver más trabajos de ellos. Es un grado altamente importante para las OPC pues tanto en el nivel 10 como en el nueve es donde 
potencialmente puede recibir más promoción de boca en boca y, por lo tanto, más ingresos en taquillas y ROI además de crítica favorable.

(8) Satisfecho. En este nivel fue acertado elegir la película, simplemente le gustó y considerará ver alguna otra de los mismos realizadores si se presenta la oportunidad. La OPC pudiera obtener fidelidad del espectador si en el futuro realiza entregas de calidad, entretenidas y que detonen algún grado de reflexión o aprendizaje el espectador.

(7) Algo satisfecho. Sigue siendo acertado haber elegido la película. Al espectador le agradaron la mayoría de las escenas, actuaciones, entre otros factores. Elementos como los efectos visuales, el guión, la banda sonora, la fotografía o edición pudieron resultar atractivos. Por otro lado, algunos factores, elementos 0 fragmentos de la película no fueron del todo satisfactorios, probablemente se sintió incómodo o aburrido durante algunos minutos en los que el film se proyectó, los cuales resultaron ser pocos.

(6) Poco satisfecho. El espectador siente algún agrado por la película, pensará que probablemente la siguiente que hagan los mismos realizadores será mucho mejor. Cabe resaltar que, probablemente, bajo este nivel, M. Night Shyamalan fue evaluado por gran parte de su público, después de que en Sexto Sentido se volvió su seguidor. Algunas películas como Señales, La Aldea, entre otras, generaron poca satisfacción a su público, pero sin duda pensaron: "probablemente la siguiente película que haga, será mejor".

(5) Indiferente. Para este tipo de consumidor o espectador no representó nada haber visto la película. Probablemente la olvide y la siguiente vez que acuda a las salas de cine no será factor decisivo para seleccionar la película que verá. Es interesante reflexionar que este pudiera ser el peor estado de satisfacción para las OPC, sus productores y directores, el cine, como séptimo arte, impregna emociones entre el público, por lo tanto, si dicha emoción no es negativa (insatisfacción) ni positiva (satisfacción) el espectador como consumidor olvidará la producción sin tomarla en cuenta, para bien o para mal, en su próxima compra de boletos.

(4) Poco satisfecho. En este nivel el espectador no le agrada del todo el film, pero considerará comprar un boleto para la próxima película de los mismos realizadores porque pudiera valer la pena darles otra 
oportunidad, ya que los antecedentes de la OPC, el director o los productores los han llevado a hacerse de una reputación, que indica que ante un descalabro cinematográfico, se pueden aprender cosas nuevas y, por lo tanto, mejorar en la próxima entrega. En este nivel el espectador pudiera hacer la mención que algún actor fue bueno o que tiene algunos momentos en los que "te ríes" o "lloras un poco".

(3) Algo insatisfecho. En este nivel hubiera sido conveniente seleccionar otra película de la cartelera. Aunque, probablemente para el espectador algún elemento como los actores, la fotografía o el sonido son rescatables. En general sintió que la película no tenía sentido o que la trama fue lenta y aburrida. Este nivel es común en películas donde el cliente menciona "la fotografía fue buena", ya que en el cine, al ser el arte de contar historias por medio de imágenes y sonidos, lo más importante es la historia que el director cuenta. Cuando ésta no "engancha" al espectador, entonces él mismo pareciera que intenta salvarla al resaltar elementos secundarios como la fotografía o el maquillaje.

(2) Insatisfecho. Para este nivel, elegir la película no fue acertado. El film simplemente no le gustó. Pudiera reflejar disonancia post compra. Definitivamente no fue una buena decisión y considerará la experiencia como negativa por lo que a la siguiente ocasión se informará mejor antes de tomar la decisión de ver otra película de los mismos realizadores.

(1) Muy insatisfecho. El espectador pensará: "No estoy satisfecho de haber visto esta película. Probablemente no vuelva a ver ninguna de los mismos realizadores". No será fundamental obtener información extra para, la próxima vez, pues no adquirir un boleto de cine para un producto de la misma OPC será definitivamente su elección.

(0) Extremadamente insatisfecho. El espectador sentirá que es una de las peores películas que ha visto en su vida. Por ningún motivo volverá a ver un film de la misma OPC, del director 0 de los productores.

Por consiguiente el espectador insatisfecho reaccionará de dos formas:

- Mediante alguna expresión de dicha insatisfacción al personal del complejo cinematográfico, criticando negativamente la película en algún medio de comunicación y redes sociales o con comentarios adversos de boca en boca. Además, probablemente no vea más películas de los involucrados 
en la OPC (productor, director, guionista, actores, entre otros.) y éstos a su vez van adquiriendo una mala fama, es decir sus películas futuras no son garantía de una buena película o de éxito taquillero.

- Mediante ninguna reacción explícita, sino más bien olvidará el film pero considerará no volver a ver películas de los realizadores, además de ir posicionando en su mente la idea de una mala película cuando tenga el sello de los nombres de los involucrados en la realización de la misma.

Como cualquier producto que es consumido por el mercado, es fundamental implementar estrategias para disminuir las insatisfacciones. Las OPC deberán escuchar y atender a los espectadores potenciales, para llevarles películas que deseen ver, mejorando el atractivo de sus entregas y resolviendo futuros problemas de insatisfacción en el espectador. Esto, posiblemente, generará mayores ventas en taquilla, mayor ROI y disminuirán la publicidad negativa proveniente principalmente de la de boca en boca, crítica o redes sociales que tanto afecta a los ingresos de las OPC.

\section{Síndrome Lozano-Barragán: Cuando las OPC no toman en cuenta los deseos y necesidades de los espectadores}

Para algunas OPC, sus productores y directores, el cine en la actualidad busca únicamente generar valores económicos, es decir una ganancia abstracta obtenida de la diferencia entre el valor social prometido de una obra y su costo de producción. Para ellos, el fin del sistema es su propia reproducción con base únicamente en el consumo y en el entretenimiento, sin ningún propósito cultural (Garduño, 2010). La ganancia podría considerarse por algunos autores como éxito empresarial (Pushpakumar \& Wijewickrama, 2008; Benzing et al., 2009; Unger et al., 2009; Chaganti \& Chaganti, 1983; Paige \& Littrell, 2002); sin embargo, no es el único factor que mide el incremento de valores económicos, ganancias o éxito; las ventas son determinantes en cualquier industria (Che et al., 2006; Ali et al., 2009; Arteaga \& Lasio, 2009; Coy et al., 2007; Alasadi \& Abdelrahim, 2008; Unger et al., 2009; Hienerth \& Kessler, 2006; Pushpakumar \& Wijewickrama, 2008) y no es la excepción en la industria cinematográfica.

Es evidente que algunas OPC sólo buscan hacer del cine un producto que entretenga de una forma hueca al espectador y olvidan la función cultural del mismo. Paralelamente, muchos otros artistas bien capacitados, con tal de 
satisfacer su ego y por su aberración a las leyes del mercado, sólo impregnan en sus productos artísticos su visión y deseos, sin considerar las necesidades del espectador por las que estaría dispuesto a adquirir un boleto en taquilla para ver sus películas. Este tipo de películas cuyo enfoque es cultural parece, en ocasiones, implicar cierto malestar entre los espectadores que los puede conducir a manifestaciones de insatisfacción poco convenientes para la obtención de beneficios económicos actuales y futuros de las OPC (Lozano et al., 2011).

Este tipo de compañías y de realizadores de films culturales, pudieran afirmar que las películas de entretenimiento y diversión que se ofrecen, son absurdas, despreciando el significado que pudieran tener en relación con la vida interior de los individuos. Estas películas carecen de simbolismos, el cual es sustituido por dramas de acción, de violencia en aumento y destrucción sin sentido (Adorno, 2001). Acusan a este tipo de productos de sólo enfocarse en su carácter comercial. Así, estas OPC llegan a ubicarse en el otro extremo de la producción cinematográfica, creando películas sin motivación de entretenimiento para el consumidor promedio, enfocándose únicamente en el carácter cultural de la película, por lo tanto, caen en un error opuesto que finalmente es también un error.

Pero, ¿acaso el cine comercial, no refleja muchas veces la parte cultural inherente al cine al contar historias con tensión política, económica y gubernamental? ¿No es el cine un reflejo de la realidad? O bien, ¿no es el cine un escaparate para el espectador que desea encontrar un mundo mejor en donde el bien, casi siempre, se impone ante la adversidad?

Incluso, este tipo de OPC enfocadas únicamente en el aspecto cultural, culpan a los consumidores potenciales, del fracaso en taquillas de sus películas, argumentando, muchas veces, que los espectadores no comprendieron la película ni el mensaje que se dio. Objetan que el público no está preparado para este tipo de obras de arte o peor aún, que carecen de cultura.

Por otro parte, quienes buscan un equilibrio en la producción cinematográfica como el cineasta español Daniel Monzón ganador del premio español Goya a la mejor dirección por la película "Celda 211" afirma: "Lo que nunca puedes hacer es culpar al público del fracaso". Además agrega que los miembros de este tipo de OPC deben "quitarse ese halo de soberbia, de petulancia..." (www.rtve.es). Así, el síndrome Lozano-Barragán (SLB) 
conceptualiza el padecimiento que sufren algunos directores cinematográficos como productores de un bien, que culpan a los consumidores o espectadores, que nos les gustó la película, del fracaso en taquilla, y además argumentan que dichos espectadores no supieron entender el producto, 0 bien, desconocen de la naturaleza cultural de la misma (Lozano \& Almaguer, 2014).

La tensión entre los factores económicos, estéticos y culturales a la hora de examinar la industria cinematográfica se debe en parte a malos entendidos. Muchas divergencias entre esos enfoques se pueden conciliar utilizando el concepto de externalidades. La creencia de que las películas con atributos culturales deseables pueden ayudar a formar mejores ciudadanos y más felices, se encuentra en el centro de argumentos económicos como estéticos y culturales.

Adaptando un poco las palabras de Wolf (1999) llegamos a que la economía cinematográfica se apoya en los retornos de un recurso humano infinito: la creatividad. Éste es el bien más valioso, origen de muchos cambios e innovaciones estéticas, culturales y económicas; tan antiguas y poco tecnológicas, como la imaginación del hombre.

Por lo tanto, para superar el SLB, las OPC y sus realizadores afectados por este mal, deben comprender que el cine tiene su origen en la creatividad, habilidad y el talento de los individuos que intervienen en su realización. Además de que tienen el potencial de generar riquezas y puestos de trabajo a través de la generación y explotación de sus propiedades intelectuales: sus películas.

Frente a los descalabros en ingresos en taquilla y en el ROI de las películas dirigidas y producidas por M. Night Shyamalan entre el 2000 y 2013 y que en algunos casos fueron provocados por el SLB en el que cayó el también empresario y que más adelante se detallará en cada uno de sus films, algunas acciones que se emplearon para evitar el SLB en la última entrega del 2015 fueron:

- Más que frustrarse por sus fracasos, aprendió de ellos. El fracaso puede generar grandes aprendizajes para no caer en errores similares en el futuro. Los Huéspedes es el producto de dicho aprendizaje adquirido entre los años 2000 y 2013. Si sólo se produjo una película con tintes artísticos y no se obtuvieron éxitos, se deberá revisar lo que se hizo mal; lo anterior puede llevar a enmendar error y pensar en cómo sacar adelante la OPC. 
El éxito en las producciones cinematográficas suelen estar precedidos de varios fracasos (Vidal, 2010).

- En "Los Huéspedes" (2015) es evidente la falta de presupuesto, al contar la historia en formato documental (aunque queda claro que es ficción), por lo tanto fue eficiente ante la falta de recursos. En ocasiones, resulta complicado encontrar inversionistas que estén dispuestos a destinar recursos para impulsar la producción y más con el antecedente de diversos fracasos. Si este es el caso, es recomendable balancear eficientemente los recursos con películas atractivas y de interés tanto para la comunidad cultural como para la mayoría de los espectadores.

- Eliminar el Ego. Es evidente que Shyamalan perdió el éxito en taquilla porque sólo buscaba satisfacer sus deseos de expresión sin considerar al espectador, y esto incluye en ocasiones, excluir de igual manera a los miembros de la producción. Es importante que las OPC, sus productores y directores, consideren que el cine es un trabajo en equipo además de tener dos compromisos sociales: creador de valores estéticos o culturales y valores económicos. Los intereses empresariales y sociales deben estar por encima de los intereses personales de cualquier integrante de este tipo de empresas.

- Evitar adoptar un modelo erróneo. Es recomendable dedicarse a la producción con un modelo comercial y cultural bien definidos e implementado de una forma que sea demandado por los espectadores. También, es imperativo para la supervivencia de las OPC, y para que los productores y directores puedan seguir haciendo películas, que dichos modelos busquen generar utilidades mediante la satisfacción de los consumidores 0 del público.

Algunas otras recomendaciones buen pudieran ser: Comprender que la comunicación de boca en boca es muy relevante para convencer a los espectadores de que vean, o no, la película; buscar siempre la mejora continua dirigida a la satisfacción de los clientes; tener apertura al cambio; seleccionar y contratar al personal con espíritu creativo y visión de negocios, entre otros. 


\section{Efecto Sharknado: Cuando las OPC olvidan la generación de valores estéticos y culturales}

En el extremo contrario de las OPC que caen en el SLB, existen aquellas empresas que únicamente se centran en la generación de valores económicos: ingresos, ROI, utilidades y en general, riquezas monetarias. Olvidan completamente la inclusión y producción de valores estéticos y culturales que deberían de cumplir por ser el cine considerado un arte y un instrumento cultural e incluso educativo. El efecto sarknado se da precisamente cuando las OPC producen filmes "huecos" o carentes de elementos dignos de ser apreciados, que provoquen algún aprendizaje 0 reflexión; y únicamente se pretende obtener dinero (Lozano \& Almaguer, 2014).

El efecto Sharknado genera problemas a las OPC por su carácter poco sustentable. Si bien, en un inicio la OPC pudiera tener éxito económico, potencialmente, este desaparece al cabo de dos o más producciones ya que los espectadores buscan algún contenido dentro de las historias que aprecian en las salas. Si estas, generan acción sin sentido o son películas absurdas, el público fácilmente pudiera alcanzar un nivel tres o menor en nuestra escala de satisfacción, es decir, "algo insatisfecho". Para no caer en el efecto Sharknado algunas OPC y el autor de la presente investigación ha propuesto diferentes estrategias (Tabla 2).

Tabla 2. Algunas recomendaciones para evitar el efecto Sharknado

Estrategias para evitar el efecto Sharknado

Las OPC deben ver al cine como un medio para canalizar la visión del director o su propia visión Considerar que las películas deben ser trascendentales

Las películas pueden ser canales que transformen algo sensitivo en cognitivo para que después los espectadores lo conviertan, nuevamente, en algo sensitivo

Los filmes son potencialmente herramientas educativas

Por medio de las películas se puede mostrar la cultura de un país, un grupo étnico, etcétera.

El cine busca armonizar el entorno

El cine da la capacidad al ser humano de reflexionar sobre la humanidad

Fuente: Elaboración propia con información de Lozano et al., 2014

Por ejemplo, el propósito de estas compañías no sólo es plantear la narrativa cinematográfica de manera donde se perciban únicamente imágenes 
y sonido con el propósito de que los espectadores pierdan el tiempo pasmados frente al televisor o la pantalla de cine. Se debe aprovechar el medio y el arrastre que tiene la industria cinematográfica para generar espacios de expresión para los directores de cine y todo su equipo de trabajo así como también motivar a la reflexión y aprendizaje al público espectador.

De igual forma, el hombre sabiéndose mortal crea arte y ciencia para ser inmortal (Almaguer et al., 2014). No hay nada más gratificante para una OPC, y para un director de cine, que su película se vea en otros países y que después de 10, 50 o más años, sus filmes sigan, de alguna manera, vigentes.

Las películas pueden ser canales que transformen algo sensitivo en cognitivo para que después los espectadores lo conviertan, nuevamente, en algo sensitivo. Si los directores de películas no tienen la facilidad de transmitir ideas escribiendo, esculpiendo o simplemente platicando, el cine se vuelve una excelente medio para comunicar ideas y sentimientos, provocando así reflexiones y sentimientos entre la audiencia.

También, se ha demostrado que los filmes y series de televisión pueden fungir como herramientas educativas (Lozano, D. 2015). Igualmente, gracias al cine hollywoodense 0 indio conocemos los estilos de vida de los ciudadanos tanto de Estados Unidos como de la India. Por medio de sus filmes apreciamos la manera de vestir, su idioma, las relaciones familiares, de pareja y en general, cualquier acto que refleje su cultura.

Pudiéramos reflexionar sobre: "para qué crear una obra de arte que no busque más que divertir sin sentido". Es responsabilidad de las OPC, sus empresarios, directores y productores usar este bien estético para crear armonía en el caos provocados por nosotros los humanos, o incluso por la misma naturaleza.

Finalmente, las OPC, los directores de películas, los actores, músicos, entre otros, tienen el poder de cambiar las formas de pensar de los consumidores e influir en ellos para que a su vez innoven en la manera tan compleja en la que actúa la sociedad. En este punto se palpa, por ejemplo, cómo al influir en las demás personas, el cine también puede incluir y generar valores políticos y sociales, motivando una mayor participación política 0 cambios en estereotipos sociales, sólo por mencionar algunos ejemplos. 
M. Night Shyamalan: análisis del balance entre un artista cinematográfico y un empresario para evitar el SLB y el efecto Sharknado

M. Night Shyamalan es un director, productor, guionista y empresario cinematográfico propietario de la OPC Blinding Edge Pictures. Shyamalan saltó a la fama con su película Sexto Sentido (1999). Para el 2000 y 2002 lanzó las producciones El Protegido y Señales, respectivamente, dichos productos fueron bien aceptados por la crítica y el público, pero no calificados como Sexto Sentido. Enseguida, su película La Aldea (2004) no recibió comentarios del todo positivos ni provocó la satisfacción de la mayoría del público. A este resultado le precedieron una serie de producciones que no tuvieron buena aceptación entre los críticos además de que los ingresos en taquilla no fueron tan prometedores como se hubieran esperado después del éxito comercial provocado por Sexto Sentido.

Su comportamiento resulta extraño para algunos productores cinematográficos, porque su potencial y buenos resultados en taquilla y con la crítica fueron desapareciendo. La venta de boletos cayó, la crítica de los expertos cinematográficos fue reprobatoria y el retorno sobre la inversión dejó de multiplicarse; indicadores importantes para cualquier OPC lucrativa. Así, elaboramos un análisis de desempeño como cineasta y como empresario, donde al lanzar Los Huéspedes (2015), Shyamalan parece concientizarse de la importancia de eliminar el SLB del que probablemente padeció así como evitar el efecto Sharknado para entonces hacerse sustentable, económicamente hablando, y recuperar con creces la inversión hecha en sus películas mientras estimula el aprecio, la reflexión y el aprendizaje de los espectadores, quienes además, se divierten.

En la Tabla 3 se muestran las principales películas dirigidas y producidas por M. Night Shyamalan y en las Figuras 4, 5 y 6 se presenta la información gráfica para su visalización. A continuación se hace una breve descripción de cada una de ellas, donde además de la sinopsis se exponen los presupuestos empleados, los ingresos obtenidos en taquilla, ROI y el porcentaje de aceptación de la película por la crítica estadounidense. Para complementar, se hace un breve análisis de la posible manifestación del SLB o del efecto Sharknado en cada una de las películas. 
Tabla 3. Principales películas producidas por Blinding Edge Pictures, OPC propiedad de M. Night Shyamalan

\begin{tabular}{|c|c|c|c|c|c|c|c|c|}
\hline Año & Película & Director & Productor & Guionista & $\begin{array}{l}\text { Presupuesto } \\
\text { en millones } \\
\text { de dólares }\end{array}$ & $\begin{array}{c}\text { Ingresos en } \\
\text { taquilla en } \\
\text { millones de } \\
\text { dólares } \\
\end{array}$ & ROI & $\begin{array}{l}\text { Porcentaje } \\
\text { de } \\
\text { aprobación } \\
\text { por la crítica }\end{array}$ \\
\hline 1999 & Sexto Sentido & Sí & No & Sí & 40 & 673 & 15.83 & $85 \%$ \\
\hline 2000 & El Protegido & Sí & Sí & Sí & 75 & 248 & 2.31 & $68 \%$ \\
\hline 2002 & Señales & Sí & Sí & Sí & 72 & 408 & 4.67 & $74 \%$ \\
\hline 2004 & La Aldea & Sí & Sí & Sí & 60 & 257 & 3.28 & $43 \%$ \\
\hline 2006 & La Dama en el Agua & Sí & Sí & Sí & 70 & 73 & 0.04 & $24 \%$ \\
\hline 2008 & El Fin de los Tiempos & Sí & Sí & Sí & 48 & 163 & 2.40 & $17 \%$ \\
\hline 2010 & El Último Maestro del Aire & Sí & Sí & Sí & 150 & 320 & 1.13 & $6 \%$ \\
\hline 2013 & Después de la Tierra & Sí & Sí & Sí & 130 & 244 & 0.88 & $11 \%$ \\
\hline 2015 & Los Huéspedes & Sí & Sí & Sí & 5 & 66.1 & 12.22 & $61 \%$ \\
\hline
\end{tabular}

Fuente: Elaboración propia con información de los portales de Internet: boxofficemojo.com y rottentomattoes.com

Figura 4. Porcentaje de aprobación por la crítica de las películas dirigidas por M. Night Shyamalan y producidas por su OPC.

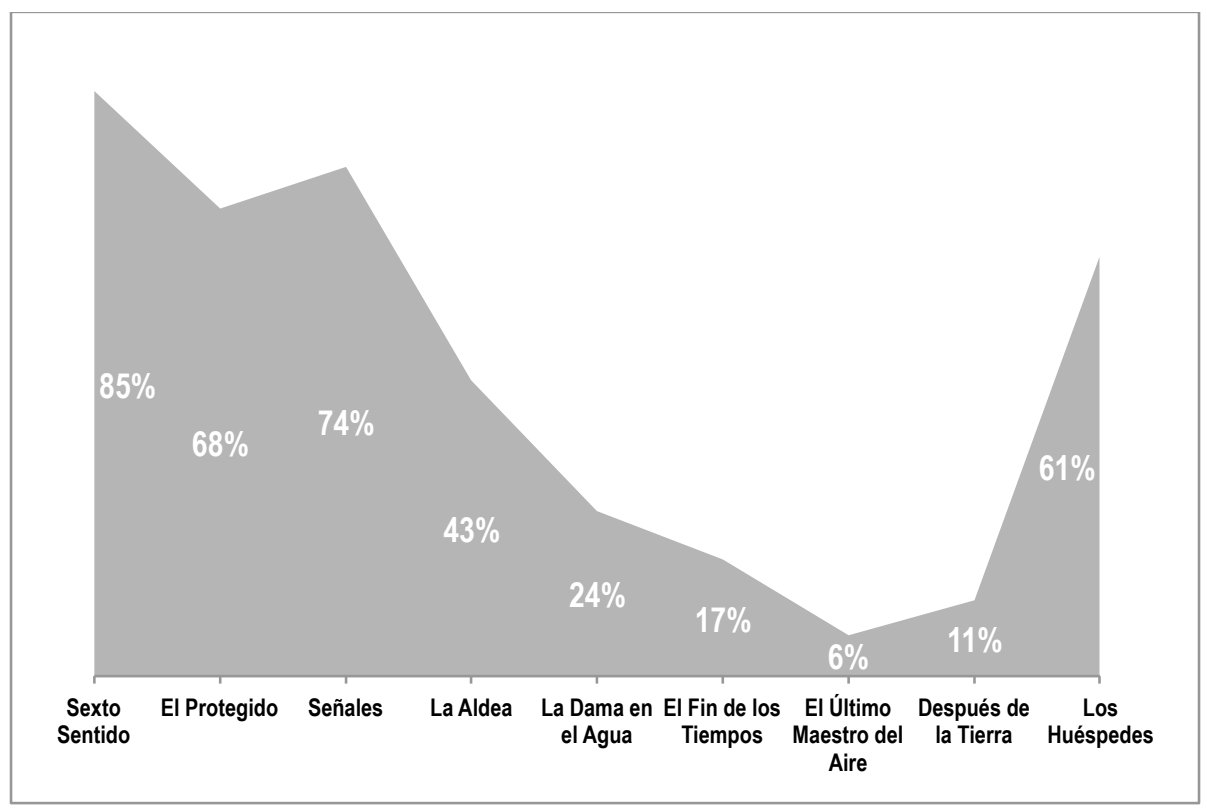

Fuente: Elaboración propia con información de Rotten Tomattoes 
Figura 5. Ingresos en taquilla en millones de dólares de las películas dirigidas por M. Night Shyamalan y producidas por su OPC

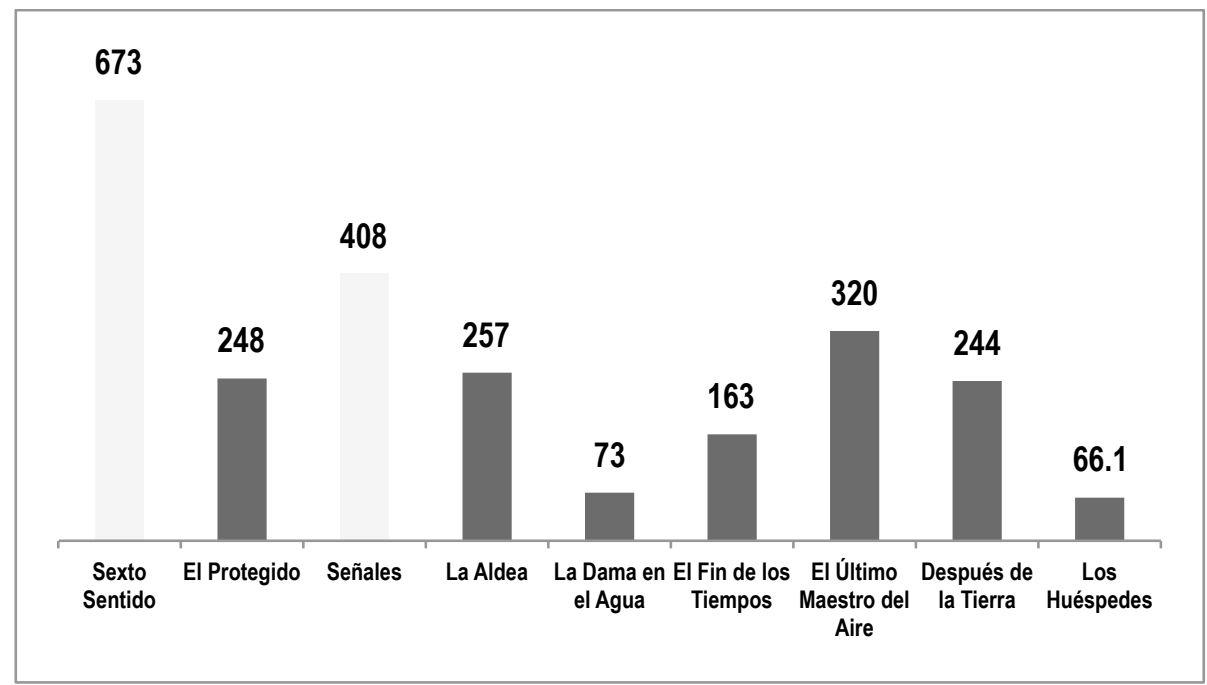

Fuente: Elaboración propia con información de Box Office Mojo

Figura 6. ROI de las películas dirigidas por M. Night Shyamalan y producidas por su OPC

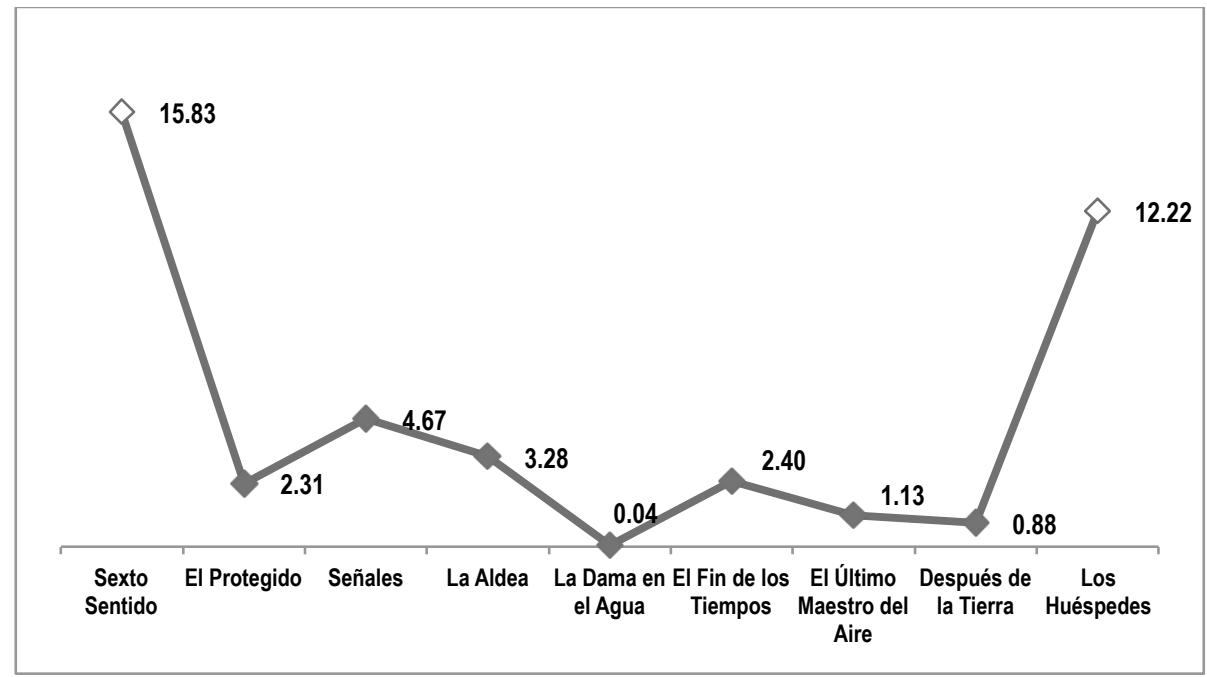

Fuente: Elaboración propia con información de Box Office Mojo 
- Sexto Sentido (1999). Es una película protagonizado por Bruce Willis que narra la historia de un niño que se comunica con espíritus que no han muerto y que busca la ayuda de un frívolo sicólogo infantil.

El éxito de la película fue tal que logró obtener seis nominaciones a los premio Óscar, además de obtener ingresos en taquilla cercanos a los 673 millones de dólares alrededor del mundo y un ROI de 15.83 veces. La película tuvo un porcentaje de aprobación del 85 , lo que la ubica en una película con muy buena aceptación entre el público según la crítica y un grado entre "satisfecho" y "muy satisfecho" según la escala propuesta en la figura 2. La misma crítica tuvo como consenso calificarla como una torcida historia de fantasmas con todo el estilo de clásico de Hollywood, pero, con todos los escalofríos de una película de terror moderna.

Por su calidad y la claridad con la que los productores, Kathleen Kennedy, Frank Marshall y Barry Mendel, otorgan, junto con el propio director, una obra que comprende una historia que el público deseó ver y sustentado en los ingresos en taquilla, Shyamalan se aleja por completo del SLB. Igualmente el contenido del mismo film, la calidad narrativa, sonora y visual, la capacidad con la que el director pone a pensar y reflexionar a los espectadores, pudiéramos aseverar que el film tampoco provoca un efecto Sharknado. Por lo tanto, Sexto Sentido se ubica con un buen generador de valores económicos y estéticos tanto para la OPC que la elaboró, como para distribuidoras, exhibidoras y el público en general.

- El Protegido (2000). Nuevamente protagonizada por Bruce Willis y ahora con Samuel L. Jackson, este film narra la historia de David Dunn que tras un accidente de tren sobrevive mientras todos los pasajeros fallecen. Un misterioso hombre le plantea la posibilidad de que se trate de un superhéroe con poderes sobrenaturales, los cuales, Dunn aún no descubre.

La crítica resultó algo dura, pero gracias a su trabajo previo, a la vez fue benevolente. El film resultó aceptable para el $68 \%$ de los críticos calificando el final como débil aunque con intriga a lo largo de la historia debido a los giros inesperados. La calificación se sustenta con la recaudación en taquilla mundial, la cual se ubicó en 248 millones de dólares además de que el ROI fue sólo de 2.31 veces.

La película catalogada según nuestra escala, prácticamente, como "algo satisfactoria", no resultó, por lo tanto, insatisfactoria para los espectadores 
que la vieron. Pareciera que las recomendaciones de boca en boca no fueron favorables según lo que pudiéramos apreciar por los ingresos en taquilla. Sin duda, Shyamalan no provoca un efecto Sharknado pues la calidad estética se plasma de manera visual y narrativa pero comienza a reflejar el SLB, pues a la falta de productores y personal objetivo que busque llevar una película que satisfaga en la medida de lo posible a los espectadores, la entrega no logra un nivel elevado que, al menos, se refleje en taquilla.

- Señales (2002). Esta es una película que generó mucha expectación cuando desde el 2001 se lanzó el tráiler. Con Mel Gibson como estrella, narra la historia de una familia que vive en una granja y encuentra misteriosos círculos de maíz en sus campos sugiriendo que algo más aterrador va a llegar.

La película se ubicó entre "algo satisfactoria" y "satisfactoria" si nos basamos en el grado de aceptación por parte de la crítica la cual fue de $74 \%$. Aunque no fue tan alta como Sexto Sentido sí se catalogó a Shyamalan como experto en crear suspenso y provocar en el público escalofríos. La película obtuvo ingresos en taquillas a nivel mundial de 408 millones de dólares y un ROI de 4.67 veces. La OPC nuevamente se aleja tanto del SLB como del efecto Sharknado. Primero, porque, según la crítica, al igual que la escala planteada en la Figura 2, la película sí provoca satisfacción entre los espectadores y dos, porque la calidad visual y narrativa, más allá de sólo buscar incrementar los valores económicos, es aceptable.

- La Aldea (2004). Esta película habla sobre una pequeña población aislada en el campo que cree que su alianza con misteriosas criaturas, que los protegen y que viven en el bosque, está por terminar.

El consenso de la crítica se pudiera interpretar como "apropiadamente aterradora, pero con un giro en la historia que al final decepciona", lo que es reflejado en el 43\% de aceptación - "indiferente"/"poco insatisfecho". Sus ingresos resultaron en 257 millones de dólares a nivel internacional mientras que el ROI fue de 3.28 veces.

Es importante considerar que en este momento, Shyamalan no cae en el SLB porque más allá de querer transmitir a su manera la historia que concibe en su mente, su objetivo fue satisfacer a los espectadores con su característico género de terror y sus peculiares giros en la historia que, 
hasta entonces, agradaban a los espectadores. Solo que en este caso el objetivo no se cumple del todo, aunque se obtuvo un ROI superior a tres, por lo que sería más apropiada calificarlo como una estrategia de producción y de marketing poco acertada. Por otro lado, no se genera un efecto Sharknado ya que el material audiovisual, la narración y el mensaje, a pesar de la insatisfacción, son de calidad y logran hacer al público reflexionar sobre los temores individuales, sociales y las imposiciones y miedos hacia las autoridades por parte de los gobernados.

- La Dama en el Agua (2006). Aborda la historia de Cleveland Heep que trabaja como personal de mantenimiento en un complejo de departamentos. Una noche, encuentra a una misteriosa joven en las galerías que pasan debajo de la piscina del complejo. Cleveland descubre que se trata de una mujer surgida de un cuento de hadas que se ha embarcado en un peligroso viaje desde la Tierra hacia su mundo.

La crítica le otorgó un $24 \%$ de aprobación, es decir, entre "algo insatisfecho" e "insatisfecho" argumentando que resulta ser una historia inverosímil con poco suspenso y escenas poco creíbles. El film pretende ser ingenioso pero resulta pretencioso y, más bien, la historia es tonta. La calidad de la película también se refleja en taquilla pues solo obtuvo ingresos por 73 millones de dólares, los más bajos de la OPC propiedad del director y un ROI de 0.04 veces a lo largo de su existencia.

EI SLB se evidencia desde la baja aceptación y los ingresos en taquilla. Una historia que no consideró las necesidades de los espectadores, sino que más bien buscó llevar un film que quería ser mostrado por el director, cabe señalar que para el presente estudio no se encontró una declaración específica, publicada en fuente confiable, que hiciera referencia a alguna posible adjudicación de culpa por parte de Shyamalan al público, del fracaso en taquilla. Por otro lado, lo "hueca" de la película provoca un efecto Sharknado, al no rescatarse valores estéticos, aprendizaje o alguna reflexión, considerable, manifestada en el público.

- El Fin de los Tiempos (2008). En este film, un profesor de ciencias, su esposa y una pequeña niña luchan por sobrevivir a una plaga que provoca en los infectados el suicidio.

Sólo al $17 \%$ de los críticos les gustó, lo que la ubica entre "muy insatisfecho" e "insatisfecho" el tercer porcentaje más bajo en las películas de Shyamalan. El consenso fue: altas expectativas que bajan rápidamente 
por la incoherencia y lo poco creíble de la trama. Los ingresos fueron de 163 millones mientras que el ROI se ubicó en 2.4 veces.

De igual forma, el SLB es evidente al ser aceptada por sólo el 17\% de los críticos. Probablemente no existió ningún estudio previo al lanzamiento que permitieran hacer los cambios a la película y generar satisfacción en los espectadores, más bien parecieran que la película fue lanzada por la OPC porque el director consideró que era un "buen" film. Por otro lado, se provoca un efecto Sharknado, pues la película no refleja ningún contenido ni genera algún valor estético. En última instancia pudiéramos argumentar que ante el producto ya terminado, las distribuidoras y exhibidoras sólo pretendieron ganar dinero.

- El Último Maestro en el Aire (2010). Sigue las aventuras de Aang, un joven sucesor de una larga línea de Avatares, quien debe dominar los cuatro elementos y detener a la Nación del juego de esclavizar a las Tribus del Agua y el Reino de la Tierra.

La película sólo le agradó al $6 \%$ de los críticos: los espectadores debieron sentirse entre "muy insatisfechos" y "extremadamente insatisfechos". El consenso fue que Shyamalan desperdicia su popular fuente de referencia con una trama incomprensible, malas actuaciones y una dirección ausente. Sus ingresos en taquilla internacional fueron de 320 millones de dólares alcanzando un $\mathrm{ROI}$ de 1.13 veces.

Se especula que para este film Shyamalan ya no escuchaba críticas, sólo deseaba hacer películas que provocaran satisfacción a su ego cayendo más profundamente bajo el SLB. Lo interesante se da que bajo esta soberbia artística también se genera un efecto Sharknado ya que El Último Maestro del Aire no refleja suficientes valores estéticos, sino pareciera que sólo se lanza para recaudar dinero en taquilla una vez que las distribuidoras se han dado cuenta que lo mejor es no perder dinero ante la escaza satisfacción que esta película provocaría a los espectadores como consumidores de un bien. También, probablemente se haya pretendido explotar el apellido Shyamalan y el potencial que tiene para obtener ingresos en taquilla.

- Después de la Tierra (2013). Con esta película, la cual solo obtuvo un $11 \%$ del agrado de los críticos, la segunda más baja, estos, llegaron a afirmar que el ejercicio resultó aburrido representando la última recaída para la 
carrera que alguna vez fue prometedora del director M. Night Shyamalan y su OPC.

La película que narra el aterrizaje riesgoso de Kitai Raige y su padre Cypher que los deja varados en la Tierra, un milenio después de que los acontecimientos catastróficos forzaran a la humanidad a salir huyendo. Con Cypher herido, Kitai debe embarcarse en un peligroso viaje para pedir ayuda.

Después de la Tierra obtuvo ingresos de 244 millones de dólares alrededor del planeta y un ROI de 0.88 veces, siendo el segundo más bajo.

Continuaron así los mismos padecimientos, poca consideración de los deseos y satisfacciones de los espectadores como consumidores, y la entrega de un producto con poco contenido estético.

- Los Huéspedes (2015). Esta película le entrega a la audiencia risas y sustos sólidos y marca un buen regreso al género de M. Night Shyamalan, según el consenso de los críticos quienes al $62 \%$ les gustó ubicándose como una película entre "poco satisfactoria" y "algo satisfactoria".

Los Huéspedes tiene simplemente como sinopsis: "algo grave pasa después de que dos niños, hijos de una madre soltera, visitan a sus abuelos".

Aunque los productos anteriores contribuyen a que los espectadores piensen detenidamente adquirir un boleto en taquilla para ver esta película, la recuperación de la OPC, y del director, pudiera resultar prometedora. Los ingresos en taquilla, cuando aún sigue en distribución mientras se efectúa la presente investigación, son de 66.1 millones de dólares, pero con una inversión de sólo cinco millones. El ROI de 12.22 veces la colocan como la segunda mejor después de Sexto Sentido y cuando aún continúa en exhibición.

Con este film, Shyamalan se aleja por completo del SLB, pues regresa a entregar producciones que desean ver los espectadores, lo que provoca satisfacción en la audiencia. Por otro lado, el claro mensaje que hace referencia a la importancia de perdonar y eliminar rencores, y cómo estos le pueden afectar, incluso, a las próximas generaciones en caso de no ser suprimidos. La OPC entrega así una película con valores estéticos que se aleja del efecto Sharknado. 


\section{Conclusiones}

Las OPC son productoras de bienes cinematográficos que por sus características generan valor económico que les permitan incrementar las riquezas de los dueños y volver rentable y sustentable a la compañía mientras que por otro lado son creadoras de valores estéticos inherentes a estos productos que buscan transmitir mensajes a los espectadores para provocar en ellos algún sentimiento, reflexión o aprendizaje.

Algunas OPC destinan mayores esfuerzos a transmitir las ideas de los artistas, directores en el caso de cine, por encima de las preferencias o necesidades de los espectadores como consumidores, lo que provoca, en ocasiones insatisfacciones en dicho público. Así, algunos directores llegan a aseverar que los espectadores no entienden la naturaleza del cine como arte, e incluso los culpan cuando los ingresos en taquilla no son satisfactorios, cayendo los realizadores en el síndrome Lozano-Barragán (SLB).

En el otro extremo están las películas carentes de contenidos que no lleven al aprecio, reflexión o aprendizaje a los espectadores, en donde la única finalidad de la OPC es incrementar sus valores económicos o riquezas, provocando entonces un efecto Sharknado.

Productores y directores de diversas OPC han desempeñado papeles que les permiten a sus empresas convertirse en entidades lucrativas. Gran parte del esfuerzo ha ido direccionado en incluir elementos narrativos como personajes principales, antagonistas o el manejo de tensión que lleven al espectador a sentir satisfacción provocada por la diversión que experimenta frente a las pantallas de cine. Países como la India, Nigeria, Estados Unidos y China cuentan con el mayor número de OPC que los ubica en los mayores productores de películas; mientras que el propio Estados Unidos, China, Japón y Gran Bretaña cuentan hoy con industrias cinematográficas que obtienen los mayores ingresos en dólares a nivel mundial. Dichas industrias han crecido, en gran medida, por la concepción que las OPC tienen del mercado y las necesidades de entretenimiento de los espectadores, que al satisfacerlas, se vuelven rentables y aseguran su crecimiento como compañías.

La satisfacción del espectador es un elemento fundamental en la búsqueda de obtener ingresos atractivos en taquillas. Si la película cumple con sus expectativas de entretenimiento y cultura, el espectador tenderá a 
sentirse satisfecho, mientras que al no cumplir dichas expectativas, se convierte en un espectador insatisfecho.

M. Night Shyamalan es un director de cine, productor y guionista dueño de la OPC Blinding Edge Pictures que saltó a la fama con su película Sexto Sentido en 1999. Sus siguientes producciones no tuvieron el éxito económico esperado provocado por el decremento en el grado de satisfacción mostrado por la audiencia. Dicho grado es establecido, en el presente estudio, con base en la aprobación de los críticos expertos. Shyamalan obtuvo ingresos de 673 millones en su película de Sexto Sentido y un ROI de 15.83 veces, mientras que el porcentaje de aprobación para este film fue de 85 . En sus siguientes producciones los ingresos fueron disminuyendo, así como el ROI y la aprobación de la crítica. El Protegido registro 248 millones de dólares, con un ROI de 2.31 veces y un $68 \%$ de aprobación. Su nivel más bajo de ingresos en taquilla lo obtuvo en el 2006 con la Dama en el Agua con lo que solamente se retornó la inversión en 0.04 veces. El Último Maestro del Aire, exhibida en el 2010, obtuvo una aprobación por parte de la crítica de $6 \%$, la cifra más baja para este director de cine.

Parte de estos resultados en taquilla, ROI y aprobación, se deben al padecimiento del SLB que manifiesta el también empresario cinematográfico. La Dama en el Agua, El Fin de los Tiempos, El Último Maestro del Aire y Después de la Tierra, principalmente, por sus cifras mostradas en la tabla 3, no reflejan estudios previos que llevaran a entregar películas que los espectadores quisieran ver en el cine y que les provocará entretenimiento y algún grado de aprendizaje o reflexión, lo que también detona un efecto Sharknado.

Cabe mencionar que pudiera ser probable que la intención no fuera esta, sino que más bien se pretendió contar historias atractivas que provocaran satisfacción entre los espectadores, más el resultado no se logró y se demuestra con las cifras de recaudación, retorno y aprobación finalmente arrojadas, de ser así, se debe analizar de manera profunda el plan de producción, desde la redacción del guión, hasta la estrategia de mercadotecnia seguida.

Con la película Los Huéspedes lanzada en 2015, Shyamalan se enfoca en eliminar las deficiencias anteriormente mostradas en sus productos. Con ingresos de 66.1 millones de dólares al momento de realizar este estudio, un $\mathrm{ROI}$ de 12.22 veces y un porcentaje de aceptación de $61 \%$, se refleja que 
gran parte del público mostró algún grado positivo de satisfacción, divirtiéndose y reflexionando sobre el mensaje que deja la narración, además de alejar al director tanto del SLB y del efecto Sharknado.

\section{Referencias}

Alasadi, R. \& Abdelrahim, A. (2008). Analysis of small business performance in Syria. Education, Business and Society: Contemporary Middle Eastern Issues, 1(1), 50-62.

Ali, M., Lai, C. \& Nawaz, M. (2009). Entreprenuer human capital and growth of small-scale industry. A case study of Sakkur Estate Area of Sindh Pakistan. Australian Journal of Basic and Applied Sciences, 3(3), 2389-2396.

Arrese, Á. (2004). Algunas consideraciones sobre la gestión de productos y contenidos de los medios: España: Comunicación y Sociedad, 15(2), 9-44.

Arteaga, M. I. \& Lasio, V. (2009). Empresas dinámicas en Ecuador: Factores de éxito y competencias de sus fundadores. Academia, Revista Latinoamericana de Administración, 42, 1-19.

Assael, H. (1999). Comportamiento del consumidor. Cd. México: Internacional Thomas Editores.

Benzing, C., Manh, H. \& Kara, O. (2009). Entrepreneurs in Turkey: A factor analysis of motivations, success factors, and problems, Journal of Small Business Management, 47(1), 58-91.

Chaganti, R. \& Chaganti, R. (1983). A profile of profitable and not-so-profitable small business. Journal of Small Business Management, 21(3), 43-51.

Che, R., Naresh, K. \& Li Yen, L. (2006). Entreprenuers success factors and escalation of small and medium-sized enterprises in Malasya, Malasya Journal of Social Sciences, 2(3), 74-80.

Coy, S. P., Shipley, M. F., Omer, K. \& Khan, R. N. (2007). Factors contributory to success: A study of Pakistan's small business owners. Journal of Developmental Entrepreneruship, 12(2), 181-198.

De Aquino, T. (2010). Suma contra los gentiles. Cd. México: Editorial Porrúa.

Freud, S. (1956). Formulations on the two principles of mental functioning. In Strachey, J. (Ed.). The standard edition of the complete psychological works of Sigmund and A. Freud. London: Hogarth.

Garduño, C. (2001). Producción y consumo: Arte y mecánica desde Benjamín y Adorno. Intersticios, $32(15), 41-56$.

Gómez, R. (2005). La Industria cinematográfica mexicana1992-2003, estructura, desarrollo, políticas y tendencias. Estudios Sobre Culturas Contemporáneas, 22(11), $249-273$.

Hienerth, C. \& Kessler, A. (2006). Measuring success in family business: The concept of configurational fit. Family Business Review, 19(2), 115-134.

Lozano, D., Barragán, J. N. \& Guerra, S. A. (2009). El cine: el negocio de la cultura, Innovaciones de Negocios, 6(12), 207-224.

Lozano, D., Barragán, J. N., Guerra, S. A. \& Zúñiga, J. (2010). Estrategias para el desarrollo cinematográfico comercial mexicano hacia los Estados Unidos. Innovaciones de Negocios. 7(13), 89-104.

Lozano, D., Barragán, J. N., Guerra, S. A. \& Treviño, E. (2011). Superando el síndrome LozanoBarragán en las organizaciones de producción cinematográfica mexicanas. Daena: International Journal of Good Conscience, 6(2), 1-16.

Lozano, D. \& Almaguer, A. (2014). Cómo incrementan el valor estético y el valor económico las organizaciones de producción cinematográfica cuando evitan el síndrome Lozano Barragán. México. Daena: International Journal of Good Conscience, 9(3), 34-52. 
Lozano, D. (2015). La producción de series de televisión por las organizaciones de producción cinematográficas (OPC) como herramienta educativa. Caso de estudio CSI, Daena: International Journal of Good Conscience, 10(2), 196-219.

Magaro, M. (2010). Two birds, one stone: Acheiving corporate social responsability trough the shareholders primacy. Indian Law Journal, 1149(85), 1149-1167.

McConnell, C. (1997). Economía: Principios, problemas y politicas. Madrid: McGraw Hill.

McFayden, S., Hoskins, C. \& Finn, A. (2000). Cultural industries from an economic/business resarch perspective, Canadian Journal of Communication. 25(1), 127-144.

Moliner, B. (2008). Determinantes del comportamiento de queja y su importancia en la segmentación de clientes insatisfechos. España: Cuadernos de Economía y Dirección de la Empresa, 36, 113150.

O'Connor, J. (1999). The definition of cultural industries. Manchester: Institute for Popular Cultures.

Paige, R., \& Littrell, M. (2002). Craft retailers' criteria for success and asociated business strategies. Journal of Small Business Management, 40(4), 314-331.

Puente, R. \& López, S. (2008). ¿Qué hacen los jóvenes cuando reciben un mal servicio? Debates IESA, 13(2), 31-36.

Puente, R. (2007). ¿Qué funciona y qué no cuando se atiende al mercado de las mayorías? Debates IESA, 12(3), 29-34.

Pushpakumari, M. D. \& Wijewickrama, A. A. (2008). Planning and performance of SME organizations: evidence from Japan. Papef presented at International Conference on Business and Management Education, Bangkok, Thailand.

Tirmizi, M. \& Rehman, K. (2009) An empirical study of consumer impulse buying behavior in local markets, European Journal of Scientific Research, 2(28), 522-532.

Turki, H. (2010). La Reuve des sciences de gestión, Direction et Gestion, 242(45), 99-111.

Unger, J. M., Keith, N., Hilling, C., Gielnik, M. M. \& Frese, M. (2009). Deliberate practice among South African small business ownwers: Relationships with education, cognitive ability, knowlwdge, and success, Journal of Occupational and Organizational Psychology, 82, 21-44

Vélez, P. (2008). Rompiendo la tradición: De describir la conducta de compra a comprender al consumidor, Pensamiento \& Gestión, 24, 1-28.

Vidal, R. \& Rolo, S. (2010) Batallas perdidas, querras ganadas: El fracaso como fuente de aprendizaje. Debates IESA, 15(2), 54-58

Wolf, M. (1999). The entertainment economy: How mega-media forces are transforming our lives. New York: Times Books. 